\title{
Apoptosis of conjunctival epithelial cells before and after the application of autologous serum eye drops in severe dry eye disease
}

\author{
Ivana Rybickova ${ }^{\mathrm{a}, \mathrm{b}}$, Viera Vesela ${ }^{\mathrm{a}}$, Ivan Fales', Pavlina Skalicka ${ }^{\mathrm{b}}$, Katerina Jirsova ${ }^{\mathrm{a}}$
}

\begin{abstract}
Aims. To assess the impact of autologous serum eye drops on the level of ocular surface apoptosis in patients with bilateral severe dry eye disease.

Methods. This prospective study was conducted on 10 patients with severe dry eye due to graft versus host disease (group 1) and 6 patients with severe dry eye due to primary Sjögren's syndrome (group 2). Impression cytology specimens from the bulbar conjunctiva were obtained before and after a three-month treatment with $20 \%$ autologous serum eye drops applied a maximum of 12 times a day together with regular therapy with artificial tears. The percentage of apoptotic epithelial cells was evaluated immunochemically using anti-active caspase 3 antibody.

Results. In group 1, the mean percentage of apoptotic cells was 3.6\% before the treatment. The three-month treatment led to a significant decrease to a mean percentage of $1.8 \%(P=0.028)$. The mean percentage of apoptotic conjunctival cells decreased from $5.4 \%$ before the treatment to $3.8 \%$ in group 2; however, these results did not reach the level of significance.

Conclusion. Three-month autologous serum treatment led to the improvement of ocular surface apoptosis, especially in the group of patients with severe dry eye due to graft versus host disease. This result supports the very positive effect of autologous serum on the ocular surface in patients suffering from severe dry eye.
\end{abstract}

Key words: apoptosis, autologous serum, dry eye disease, caspase 3, conjunctival epithelium

Received: June 15, 2015; Accepted with revision: January 20, 2016; Available online: February 29, 2016 http://dx.doi.org/10.5507/bp.2016.001

aLaboratory of the Biology and Pathology of the Eye, Institute of Inherited Metabolic Disorders, General University Hospital and First Faculty of Medicine, Charles University in Prague, Prague, Czech Republic

${ }^{b}$ Department of Ophthalmology, General University Hospital and First Faculty of Medicine, Charles University in Prague, Prague, Czech Republic

'Department of Cell Therapy and Cord Blood Bank Czech Republic, Institute of Haematology and Blood Transfusion, Prague, Czech Republic Corresponding author: Katerina Jirsova, e-mail: katerina.jirsova@lf1.cuni.cz

\section{INTRODUCTION}

Dry eye disease (DED) is a multifactorial disease of the tears and ocular surface that results in symptoms of discomfort, visual disturbance, and tear film instability ${ }^{1}$. The etiology of DED involves multiple factors, including chronic graft versus host disease (GvHD) and primary Sjögren's syndrome. GvHD is a complication of allogeneic stem cell or bone marrow transplantation. The immune system of the graft recognizes the recipient and attacks the host cells. Sjögren's syndrome is a chronic autoimmune disease in which the immune system attacks especially the salivary and lacrimal glands. High levels of pro-inflammatory chemokines have been detected in the tears and on the ocular surface of the conjunctiva in both GVHD and Sjögren's syndrome patients ${ }^{2}$. The release of pro-inflammatory mediators may lead to ocular surface damage as well as to lacrimal epithelial cell dysfunction and apoptosis ${ }^{3-4}$.

The damage to the ocular surface caused by DED is characterized mostly by squamous metaplasia of the epithelial cells, the gradual loss and finally absence of conjunctival goblet cells, the presence of inflammatory cells on the ocular surface, increased osmolarity and also an increased number of apoptotic epithelial cells ${ }^{5-6}$.
The role of apoptosis and inflammation in the pathogenesis of DED has been studied extensively. Increased levels of proapoptotic factors on the ocular surface and in the tear film have been demonstrated in DED (ref. ${ }^{7-10}$ ) and have been found to be significantly higher than in normal eyes ${ }^{7,9}$. As a consequence, inflammation and apoptosis are under investigation as potential therapeutic targets for this condition. Several studies have shown the effect of topical cyclosporine, a calcineurin inhibitor that decreases the release of proinflammatory cytokines, inhibits $\mathrm{T}$ lymphocytes and inhibits apoptosis on the ocular surface cells ${ }^{8,10-12}$.

The level of apoptosis of tissue samples is usually assessed immunohistochemically by the terminal deoxynucleotidyl transferase-mediated dUTP-nick end labeling (TUNEL) assay or by the immunodetection of caspase-3, $-8,-9$ or cleaved poly(ADP-ribose) polymerase (PARP; a nuclear DNA-binding protein) (ref. ${ }^{13-17}$ ). Transmission electron microscopy and dye nuclear staining can be used for morphologic characterization of nuclear changes during apoptosis ${ }^{13,18}$.

Caspase- 3 plays a key role in the process of apoptosis. It belongs to the cysteine-aspartic acid protease (caspase) family. This protein is synthesized as an inactive proenzyme and is activated soon after the onset of apoptosis in- 
duced by a series of different signals such as, transforming growth factor $\beta$ (TGF $\beta$ ), tumor necrosis factor (TNF) or Fas receptor. Caspase- 3 is activated by proteolysis mediated by upstream proteases (e.g., caspase-8, -9 and -10) and the granzyme B. Active caspase- 3 proteolytically cleaves and thus activates other caspases (e.g., execution-phase caspases-6, -7 and -9 ) and targets in the cell ${ }^{19-20}$.

The treatment of DED comprises both non-pharmacological and pharmacological approaches. Tear retention strategies comprise lacrimal duct occlusion by punctal plugs or surgical methods. Pharmacological approaches comprise above all hydration of the ocular surface by artificial tears; anti-inflammatory and immunosuppressory agents are used to improve the symptoms of chronic inflammation ${ }^{21,22}$.

It has been shown that autologous serum (AS) eye drops can be profitably used in the treatment of DED of various etiologies, including GvHD and Sjögren's syndrome $^{23-26}$. Their effectiveness is mainly attributed to the presence of various substances including growth factors such as TGF $\beta$, epidermal growth factor (EGF), nerve growth factor and insulin-like growth factor 1; neurotrophic factors (substance P); bacteriostatic factors (lysozyme, immunoglobulins); fibronectin and vitamin A. Almost all of these substances are also present in normal tears ${ }^{27-28}$. Several experiments have shown that AS eye drops suppress apoptosis in the ocular surface epithelium and increase goblet cell density in dry eye; the causal effect of albumin, the major protein in serum, has been suggested. In animal and in vitro studies of dry eye, albumin improved cellular damage and suppressed apoptosis in the ocular surface epithelium ${ }^{29-31}$.

The aim of this study was to assess the level of apoptosis in conjunctival epithelial cells in patients suffering from severe DED before and after a three-month treatment with $20 \%$ AS-eye drops.

\section{MATERIALS AND METHODS}

\section{Patients}

Sixteen adult patients (13 females, 3 males) with a mean age of $49 \pm 12$ (31 - 71) years suffering from bilateral severe DED were eligible for enrollment into the study. The study followed the tenets set forth in the Helsinki declaration and was approved by the institutional ethics committee. Informed consent was obtained from all patients. Severe DED was defined by the following inclusion criteria: Schirmer test I less than $5 \mathrm{~mm}$ (measuring reflex tear secretion over five minutes while allowing natural blinking); tear film breakup time less than five seconds ${ }^{32}$.

The cause of DED was attributed to GvHD in 10 patients (group 1; 7 females, 3 males) and primary Sjögren's syndrome in 6 individuals (group 2; women only). Chronic GvHD developed following allogeneic hematopoietic stem cell transplantation due to various underlying hematopoietic diseases (acute or chronic myeloid leukemia, T-cell lymphoma, myelodysplastic syndrome, primary myelofibrosis or acute lymphoblastic leukemia).
All patients had undergone previous lower or both lower and upper punctual occlusion. Twelve patients had been treated with preservative-free artificial tear eye drops, while four patients used artificial tears containing Purite oxychloro complex or Polyquad preservatives. Nine patients used, in addition, an ocular lubricant gel containing cetrimide preservative. Fifteen patients received local corticosteroids as permanent medication.

Six patients, all in the GvHD group, were on systemic immunosuppressive therapy (four of them received CsA and two tacrolimus therapy), in each case together with a low dose of systemic corticosteroids. Five patients in the GvHD group received systemic antiviral therapy (acyclovir or valaciclovir). From the SS group, one patient received systemic corticosteroids and three patients hydroxychloroquine. The therapy was not changed for at least two months before the application of AS nor during the study.

\section{AS eye drop preparation and application}

AS eye drops were prepared from $40 \mathrm{ml}$ of venous blood of each patient, as described ${ }^{33}$. After centrifugation ( $3000 \mathrm{~g}$ for $15 \mathrm{~min}$ ) the supernatant serum was removed under sterile conditions in a biohazard hood and diluted with isotonic buffered saline solution to $20 \%$. The AS eye drops were aliquoted into $10 \mathrm{ml}$ dark sterile vials protected from ultraviolet light (SANO, Dr. Kulich Pharma, Czech Republic) and kept frozen at $-20{ }^{\circ} \mathrm{C}$. Serology tests (HIV, HBV, HCV, Treponema pallidum) and microbiology control were performed (all with negative results).

The patients administered AS eye drops for three months, approximately 15 minutes after the application of artificial tears. The number of AS applications was dependent on the number of artificial tear applications; most of the patient applied AS six to ten times daily.

\section{Impression cytology and immunochemistry}

Impression cytology was carried out twice (before and after three-month AS treatment) using Biopore membranes (MILLICELL®-CM, PICM 01250, Millipore, Ireland). Samples of the superficial epithelium were harvested from the lower-nasal bulbar conjunctiva.

To fix the cells and to release the membrane from the plastic holder, the samples were treated for one minute with concentrated cold acetone. Then, the membranes were placed cell side up on round $12 \mathrm{~mm}$ coverslips, on which they remained adhered during all subsequent immunocytochemical steps using a drop method. Cells were permeabilized with $0.2 \%$ Triton (Triton X-100, SigmaAldrich Corp, St Luis, USA) in phosphate buffered saline (PBS), blocking was performed using $2.5 \%$ bovine serum albumin for $20 \mathrm{~min}$ (bovine serum albumin - Fraction V, Sigma-Aldrich Corp, St. Louis, USA). To detect the active form of caspase-3 only, the specimens were incubated for one hour with monoclonal rabbit anti-Caspase-3 (active) antibody (PN 04-439, Millipore, Ireland, 1:100), then incubated for one hour with tetramethylrhodamine-conjugated donkey anti-rabbit IgG (Jackson ImmunoResearch Laboratories, City, UK, 1:200). After rinsing in PBS, samples were mounted with Vectashield mounting me- 
dium (Vector Laboratories, Inc. Burlingame, USA) with propidium iodide. The rhodamine label was visualized by an Olympus BX51 fluorescence microscope (Olympus Co., Tokyo, Japan) at a magnification of 100x. Images were taken using a Vosskühler VDS CCD-1300 camera (VDS Vosskühler GmbH, Germany). The percentage of apoptotic cells was calculated from 10 - 20 non-overlapping images using an NIS Elements image analysis system (Laboratory Imaging, Czech Republic).

\section{Statistical analysis}

The Wilcoxon nonparametric test for two correlated samples involving matched pairs was used to compare the laboratory data before and after AS eye drop treatment for the two groups. Statistical significance was considered to be a p-value $<0.05$.

\section{RESULTS}

The confluence of most imprints ranged from 70 $90 \%$. The majority of cells were of epithelial origin with a nucleus-cytoplasm ratio of 1:2 to 1:4 (Fig. 1A). After the three-month treatment, the mean percentage of these cells increased from $86 \pm 21$ to $91 \pm 11 \%$. Squamous cells with a nucleus-cytoplasm ratio of 1:5 or lower (Fig. 1B) were found in $12 \pm 22 \%$ and in $8 \pm 12 \%$ samples before and after the treatment, respectively. Goblet cells were present only in four samples (Fig. 1C); the density of the goblet cells reached $5 \%$ or less.

Before AS treatment, the mean percentage of apoptotic cells was $3.6 \pm 5.9$ in group 1 and $5.4 \pm 4.7 \%$ in group 2. The percentage of such cells differed markedly between the individual patients. In $44 \%$ ( 7 patients), the percentage of apoptotic cells before AS application did not exceed $1 \%$. In $31 \%$ ( 5 patients), the percentage was lower than $5 \%$; however, $5 \%$ was exceeded by one patient from group 1 and by three patients from group 2 .

The three-month application of AS eye drops led to a significant decrease in the percentage of apoptotic epithelial cells to a mean of $1.8 \pm 3.8 \%(P=0.028)$ in group 1 . However, the decrease of the mean values to $3.8 \pm 5.5 \%$ in group 2 was not found to be statistically significant $(P=0.345)$. For individual patients, the percentage of apoptotic cells decreased in 12 patients, increased in 2 and did not change in 2 patients. Apoptosis in goblet cells was rare.

\section{DISCUSSION}

Dry eye disease can be considered as a public health problem and one of the most common conditions seen by eye care practitioners ${ }^{34}$. However, the pathogenesis and treatment of DED still remain under investigation and have not yet been fully elucidated.

Here we show that three months treatment with AS led to a significant decrease in the mean percentage of apoptotic conjunctival cells in GvHD patients from 3.6 to $1.8 \%$. A decrease in mean values (from 5.4 to $3.8 \%$ )
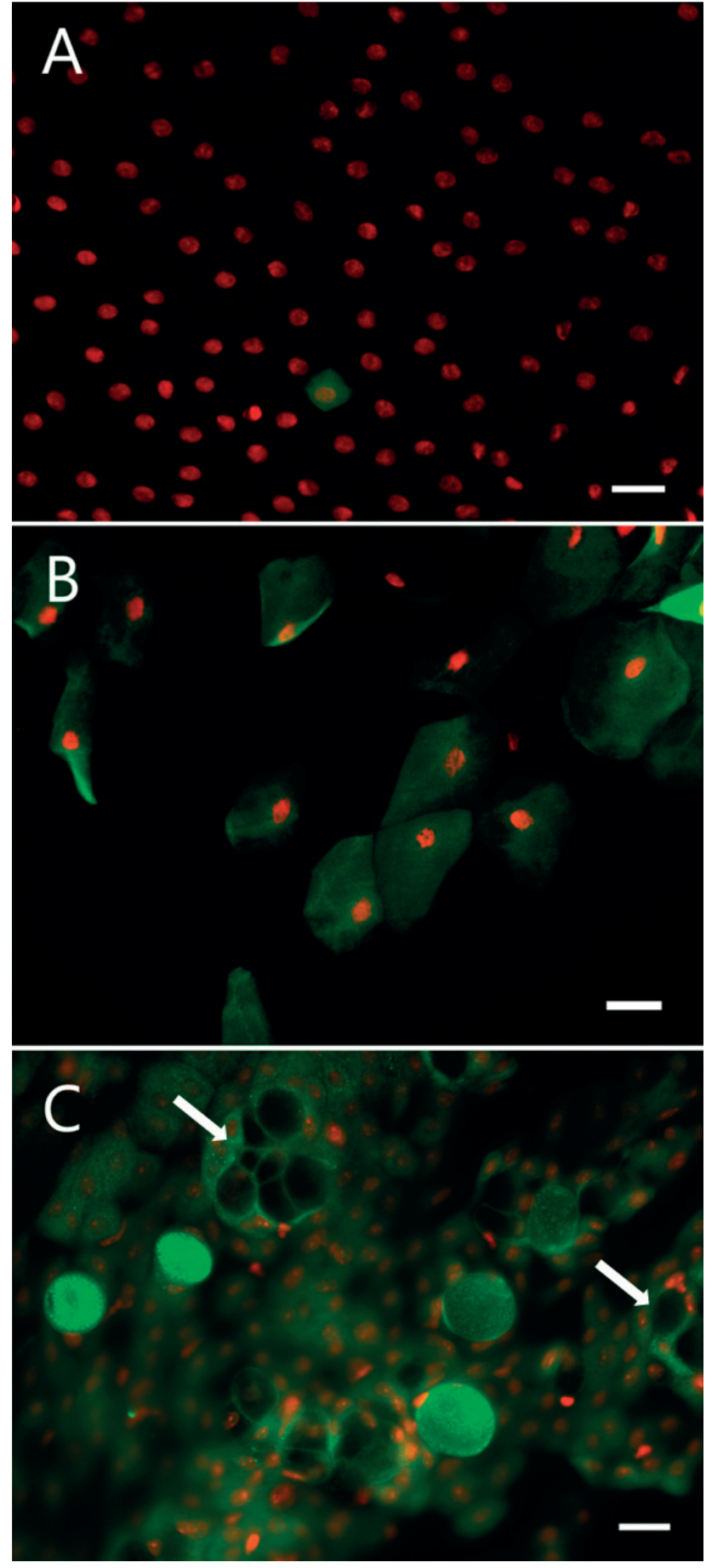

Fig. 1. The morphological differences of the ocular surface cells: epithelial cells with a nucleus-cytoplasm ratio of $1: 2$ to 1:4 (A), squamous cells with a nucleus-cytoplasm ratio of 1:5 or lower (B), goblet cells (arrows) (C). Green fluorescence of apoptotic cells after anti-active caspase 3 antibody immunochemical detection, scale bar represents $50 \mu \mathrm{m}$.

was also detected in the group of patients with primary Sjögren's syndrome. However, these results did not reach the level of statistical significance, most probably due to the small number of patients in this group.

Our results showed that positive staining using anticaspase- 3 was detected in conjunctival epithelial cells with a nucleus-cytoplasm ratio ranging from 1:2 to 1:4 as well as in squamous cells with a lower nucleus-cytoplasm ratio. 
After treatment with AS, the mean percentage of squamous cells in the samples decreased from 12 to $8 \%$; this was consistent with an improvement in the condition of the ocular surface. We did not assess anti-caspase 3 positivity in goblet cells separately because they were present in only four samples. The density of goblet cells in these samples was less than $5 \%$ and apoptosis was very rare.

In our previous study, the level of apoptosis assessed by the terminal deoxynucleotidyl transferase dUTP nick end labeling (TUNEL) assay in DED patients of various etiologies decreased significantly from 4.0 to $2.3 \%$. On the other hand, no significant difference in the number of apoptotic cells before and after AS treatment was found from assessing the degree of granular condensation of the nuclear chromatin related to apoptosis ${ }^{33}$. Thus, it appears that TUNEL and caspase-3 immunohistochemical analysis of apoptotic epithelial conjunctival cells is more suitable for the detection of apoptotic cells compared to assessing the extent of granular condensation of the nuclear chromatin, representing both early and advanced stages of apoptosis ${ }^{18}$.

\section{CONCLUSION}

Apoptosis may be one of the key factors in the pathogenesis of DED and thus is a therapeutic target for this condition. Caspase-3 detection is a reliable approach for identifying apoptotic cells on the surface of the ocular conjunctiva. A decrease in the number of conjunctival cells undergoing apoptosis in patients with severe DED was found, particularly in GvHD patients. Our results support the very positive effect of AS on the ocular surface. Thus this treatment has the potential to become a common therapy for severe DED.

Acknowledgment: This work was supported by the research project IGA NT/12376-4. Institutional support was provided by PRVOUK-P24/LF1/3 program of the Charles University in Prague. KJ was supported by project LM 2010004 BBMRI_CZ.

Author contributions: IR: caspase detection, microscopy, statistical analysis, manuscript preparation; VV: AS preparation, impression cytology; IF: AS preparation; PS: enrollment of patients into the study, clinical examinations; KJ: impression cytology, microscopy, manuscript preparation.

Conflict of interest statement: None declared.

\section{REFERENCES}

1. Dry Eye Workshop The definition and classification of dry eye disease: Report of the Definition and Classification Subcommittee of the International Dry Eye Workshop. Ocul Surf 2007;5:75-92.

2. Westekemper H, Meller S, Citak S, Schulte C, Steuhl KP, Homey B, Meller D. Differential chemokine expression in chronic GVHD of the conjunctiva. Bone Marrow Transplantation 2010;45:1340-6.

3. Zhu Z, Stevenson D, Ritter T, Schechter JE, Mircheff AK, Kaslow HR, Trousdale MD. Expression of IL-10 and TNF-inhibitor genes in lacrimal gland epithelial cells suppresses their ability to activate lymphocytes. Cornea 2002;21:210-4.
4. Zoukhri D. Effect of inflammation on lacrimal gland function. Exp Eye Res 2006;82:885-98.

5. Pflugfelder SC, Solomon A, Stern ME. The diagnosis and management of dry eye: a twenty-five-year review. Cornea 2000;19:644-9.

6. McGinnigle S, Naroo SA, Eperjesi F. Evaluation of dry eye. Surv Ophthalmol 2012;57:293-316.

7. Brignole F, De Saint-Jean M, Goldschild M, Becquet F, Goguel A, Baudouin C. Expression of Fas-Fas ligand antigens and apoptotic marker APO2.7 by the human conjunctival epithelium. Positive correlation with class II HLA DR expression in inflammatory ocular surface disorders. Exp Eye Res 1998;67:687-97.

8. Gao J, Schwalb TA, Addeo JV, Ghosn CR, Stern ME. The role of apoptosis in the pathogenesis of canine keratoconjunctivitis sicca: the effect of topical Cyclosporin A therapy. Cornea 1998;17:654-63.

9. Brignole F, Pisella PJ, Goldschild M, De Saint Jean M, Goguel A, Baudouin C. Flow cytometric analysis of inflammatory markers in conjunctival epithelial cells of patients with dry eyes. Invest Ophthalmol Vis Sci 2000;41:1356-63.

10. Brignole F, Pisella PJ, De Saint Jean M, Goldschild M, Goguel A Baudouin C. Flow cytometric analysis of inflammatory markers in KCS: 6-month treatment with topical cyclosporin A. Invest Ophthalmol Vis Sci 2001;42:90-5.

11. Kaswan R. Characteristics of a canine model of KCS: effective treatment with topical cyclosporine. Adv Exp Med Biol 1994;350:583-94.

12. Ridder $\mathrm{WH}^{3 \text { rd }}$. Ciclosporin use in dry eye disease patients. Expert Opin Pharmacother 2008;9:3121-8.

13. Yeh S, Song XJ, Farley W, Li DQ, Stern ME, Pflugfelder SC. Apoptosis of ocular surface cells in experimentally induced dry eye. Invest Ophthalmol Vis Sci 2003;44:124-9.

14. Strong B, Farley W, Stern ME, Pflugfelder SC. Topical cyclosporine inhibits conjunctival epithelial apoptosis in experimental murine keratoconjunctivitis sicca. Cornea 2005;24:80-5.

15. Chen W, Zhang X, Liu M, Zhang J, Ye Y, Lin Y, Luyckx J, Qu J. Trehalose protects against ocular surface disorders in experimental murine dry eye through suppression of apoptosis. Exp Eye Res 2009;89:311-8.

16. Gurdal C, Genc I, Sarac O, Gonul I, Takmaz T, Can I. Topical cyclosporine in thyroid orbitopathy-related dry eye: clinical findings, conjunctival epithelial apoptosis, and MMP-9 expression. Curr Eye Res 2010;35:771-7.

17. Zhang X, Chen W, De Paiva CS, Corrales RM, Volpe EA, McClellan AJ, Farley WJ, Li DQ, Pflugfelder SC. Interferon-gamma exacerbates dry eye-induced apoptosis in conjunctiva through dual apoptotic pathways. Invest Ophthalmol Vis Sci 2011;52:6279-85.

18. Jirsova K, Mandys V. Induction of micronuclei and granular chromatin condensation in human skin fibroblasts influenced by cisplatin (cis-DDP) in vitro. Mutat Res 1994;310:37-44.

19. Porter AG, Janicke RU. Emerging roles of caspase-3 in apoptosis. Cell Death Differ 1999;6:99-104.

20. Mcllwain DR, Berger T, Mak TW. Caspase functions in cell death and disease. Cold Spring Harb. Perspect Biol 2013;5:a008656.

21. Wolkoff P, Nojgaard JK, Troiano P, Piccoli B. Eye complaints in the office environment: precorneal tear film integrity influenced by eye blinking efficiency. Occup Environ Med 2005;62:4-12.

22. Lemp MA. Management of dry eye disease. Am J Manag Care 2008;14:S88-101.

23. Poon AC, Geerling G, Dart JKG, Fraenkel GE, Daniels JT. Autologous serum eyedrops for dry eyes and epithelial defects: clinical and in vitro toxicity studies. British Journal of Ophthalmology 2001;85:118897.

24. Ogawa $Y$, Okamoto $S$, Mori T, Yamada M, Mashima $Y$, Watanabe $R$ Kuwana M, Tsubota K, Ikeda Y, Oguchi Y. Autologous serum eye drops for the treatment of severe dry eye in patients with chronic graftversus-host disease. Bone Marrow Transplantation 2003;31:579-83.

25. Kojima T, Ishida R, Dogru M, Goto E, Matsumoto Y, Kaido M, Tsubota $K$. The effect of autologous serum eyedrops in the treatment of severe dry eye disease: A prospective randomized case-control study. American Journal of Ophthalmology 2005;139,242-6.

26. Na KS, Kim MS. Allogeneic Serum Eye Drops for the Treatment of Dry Eye Patients with Chronic Graft-Versus-Host Disease. Journal of Ocular Pharmacology and Therapeutics 2012;28:479-83.

27. Geerling G, MacLennan S, Hartwig D. Autologous serum eye drops for ocular surface disorders. British Journal of Ophthalmology 2004;88:1467-74

28. Bradley JC, Simoni J, Bradley RH, McCartney DL, Brown SM. Time- 
and Temperature-Dependent Stability of Growth Factor Peptides in Human Autologous Serum Eye Drops. Cornea 2009;28:200-5.

29. Higuchi A, Ueno R, Shimmura S, Suematsu M, Dogru M, Tsubota K. Albumin rescues ocular epithelial cells from cell death in dry eye. Curr Eye Res 2007;32:83-8.

30. Kojima T, Higuchi A, Goto E, Matsumoto Y, Dogru M, Tsubota K. Autologous serum eye drops for the treatment of dry eye diseases. Cornea 2008;27:S25-30.

31. Quinto GG, Camacho W, Castro-Combs J, Li L, Martins S A, Wittmann P, Campos M, Behrens A. Effects of topical human amniotic fluid and human serum in a mouse model of keratoconjunctivitis sicca. Cornea 2012;31:424-30.
32. Pflugfelder SC, Geerling G, Kinoshita S, Lemp MA, McCulley J, Nelson D, Novack GN, Shimazaki J, Wilson C. Management and therapy of dry eye disease: Report of the Management and Therapy Subcommittee of the international Dry Eye WorkShop (2007). Ocular Surface 2007;5:163-78.

33. Jirsova K, Brejchova K, Krabcova I, Filipec M, Al Fakih A, Palos M, Vesela V. The Application of Autologous Serum Eye Drops in Severe Dry Eye Patients; Subjective and Objective Parameters Before and After Treatment. Current Eye Research 2014;39:21-30.

34. O'Brien PD, Collum LM. Dry eye: diagnosis and current treatment strategies. Curr Allergy Asthma Rep 2004;4:314-9. 